\title{
INFRARED INTERNAL REFLECTION SPECTROSCOPY OF HUMAN ENAMEL SURFACES
}

\author{
D. J. KRUTCHKofF* and N. H. RowE \\ Department of Oral Pathology, School of Dentistry, University of Michigan, \\ Ann Arbor, Michigan 48104, U.S.A. \\ and \\ H. B. MARK, JR. \\ Department of Chemistry, University of Michigan, Ann Arbor, \\ Michigan 48104, U.S.A.
}

\begin{abstract}
Summary-Techniques previously utilized for chemical analysis of enamel surfaces are generally unsuitable for in-vivo testing. This study explored the utility of internal reflection spectroscopy (IRS) as a non-destructive method for enamel-surface analysis.

Powders (enamel plus reference inorganic materials) and solids (flattened and unaltered enamel slabs) were analysed by IRS. Most samples were mounted in a Wilks Model 45 Micro-ATR Accessory and scanned from 2 to $25 \mu \mathrm{m}$ to obtain i.r. spectra. Comparability of IRS data with that of transmission methods was established. Typical apatitic $\nu_{3}$ phosphorous-oxygen absorption was observed at $1090 \mathrm{~cm}^{-1}$ and $1040 \mathrm{~cm}^{-1}$ in spectra of natural fluorapatites and enamel powders. Spectral differences were demonstrated between powdered and intact enamel. The presence of carbonate was confirmed in both powdered and solid enamel. Intact surface enamel and fluorapatites failed to absorb at $630 \mathrm{~cm}^{-1}$. Weak absorption at $630 \mathrm{~cm}^{-1}$ after disking of the enamel surface was interpreted as a relative loss of fuorapatite due to mechanical reduction to subsurface levels.

Internal reflection spectroscopy enabled subtle chemical differences in enamel surface to be distinguished. This non-destructive method offers promise for in-vivo enamel surface analysis.
\end{abstract}

SURFACE enamel represents the initial barrier to dental caries. Investigators have long realized that a thorough knowledge of the chemical nature of enamel is a prerequisite to the effective control of dental caries at its inception. While this rationale for enamel research is unquestioned, inability to detect subtle changes in the actual enamel surface is a shortcoming of available techniques. In addition, most methods require sample destruction to accomplish the analytical procedure. Thus available testing is limited not only by insensitivity to surface properties but also by unsuitability for in-vivo analysis.

At present, the dynamics of the incipient carious lesion are difficult to assess with precision. Magnification of tooth surfaces to several hundred times original dimensions is possible with light microscopy. Scanning electron microscopy affords even greater resolution (HofFMAN, McEwAN and DREw, 1968). However, the chemical nature of surface changes cannot be determined by these methods. In addition to the

* Present address: Health Science Center, University of Louisville, Louisville, Ky. 40202, U.S.A. 
morphologic capabilities of the scanning electron microscope, the electron microprobe is able to measure relative concentrations of various elements (FRANK, CAPITANT and GoNI, 1966). However, both methods require near-vacuum conditions and are thus unsuitable for in-vivo determinations.

Infrared absorption spectroscopy has proved useful in various phases of nondestructive analysis (CRISLER, 1966). This analytic method is based upon the vibrational properties of most covalent bonds. Atoms of such bonds consistently undergo vibration at certain frequencies. The exact frequency of vibration is determined by the sum of independent variables (e.g. atomic weight, inter-atomic distance, electromagnetic influence, external forces, etc). Most inter-atomic vibrations fall within the range of the fundamental i.r. spectrum $\left(0.6\right.$ to $\left.12.0 \times 10^{13} \mathrm{c} / \mathrm{s}\right)$. Infrared energy is absorbed by the sample when vibrational and source frequencies are identical and the vibration coincides with a change of dipole moment. The change in dipole moment is the coupling mechanism that allows energy exchange. Once absorbed, energy is expended as heat in subsequent collisions with adajcent molecules. Different types (modes) of atomic vibration are designated by the Greek letter, "Nu" (v) and subscript $1,2,3,4$, etc. Normally only certain modes are infrared-active since only vibrations involving a change in dipole moment absorb incident energy. Additional information may be obtained from the classic work of HERTZBERG (1945) and the more recent, non-technical work of KeNDALL (1965).

With transmission spectroscopy, the sample to be analysed is suspended within a transparent window matrix such as $\mathrm{KBr}$ and placed between the IR source and the detector. The difference between the sample spectra and that of the suspending matrix alone is attributed to sample absorption. Transmission methods have proven useful for analysis of powders, liquids and gases. Such methods, however, are impractical for opaque or thick objects as source energy is either absorbed and/or reflected so that none is able to reach the detector. External (specular) reflectance spectroscopy has been employed for the analysis of optically opaque samples. Source energy is directed toward a surface with reflectance (absorbance) plotted as a function of wavelength (or frequency). This method is useful for the analysis of highly reflective samples, e.g., metals, possessing extremely smooth, even surfaces (PoLCHLOPEK, 1966). Irregular, non-reflective samples do not lend themselves to analysis by this method as they scatter or absorb a majority of the incident beam with little or no reflected energy reaching the detector.

Internal reflection spectroscopy (IRS), like specular reflectance, also utilizes the principles of reflected light energy. However, it differs in that the reflected beam is partially independent of the "physical" nature of the sample surface. Internal reflection spectroscopy involves propagation of an energy beam within a transparent prism material (internal reflection element). The sample to be analysed (of low refractive index relative to prism refractive index) is positioned such that the energy beam is reflected internally at a prism surface corresponding to sample contact. Upon striking the prism surface at an angle $(\theta)$ greater than the critical angle $\left(\theta_{c}\right)$, the incident beam is totally reflected provided that the adjacent material of low refractive index does not absorb $(K=0)$ at the wavelength of the incident beam (HARRICK, 1967). The critical 
angle is a dependent variable and is determined by the following expression: (rearrangement of Snell's Law and Fresnel's equations)

$$
\operatorname{Sin} \theta_{c}=\frac{N_{2}}{N_{1}}
$$

where $N_{2}$ is the refractive index of the sample material and $N_{1}$ is the refractive index of the IRS prism. Note that $N_{1}$ must be greater than $N_{2}$ for total internal reflectance to occur. The critical angle otherwise becomes undefinable since light is refracted through the interface.

When $\theta$ is greater than $\theta_{c}$, the incident beam is generally totally reflected. However, at each reflection, the electric vector penetrates the rarer medium a fraction of a wavelength (the "evanescent wave"). If the material in contact with the prism absorbs light at a given wavelength $(K \neq 0)$, reflection at that point is no longer total in that the beam is attenuated in proportion to the optical properties of the absorbing, rarer medium. The use of multiple internal reflection increases sensitivity by providing multiple opportunities for absorption without energy loss at transparent wavelengths (HARRICK, 1967). Infrared IRS thus represents the coupling of attenuated total reflection (ATR) with infrared spectroscopy to obtain a "fingerprint" of the chemical nature of the sample surface.

Enamel is not of homogeneous composition. Numerous studies have demonstrated the inverse relationship between fluoride content and depth from the surface (Brudevold, Steadman and Smith, 1960; IsaAC et al., 1958; Mellberg et al., 1968). Other enamel constituents also demonstrate variable concentrations that appear to be depth dependent (BatTistone, Feldman and Reba, 1967; SöremarK and Grøn, 1966). However, the molecular nature of these differences in chemical composition remains unknown. At present, there are no analytical means applicable to in-vivo testing that permit determination of subtle chemical differences in enamel surface. This study was conducted to assess the ultility of infrared internal reflection spectroscopy for enamel surface analysis.

\section{MATERIALS AND METHODS}

Samples were divided into two groups; powders and solids. Powders included reference inorganic compounds, synthetic and naturally occurring apatites, plus powdered enamel (Table 1). Small particle-size powder samples were obtained by grinding, when necessary, in an agate mortar and pestle. Enamel was prepared by fracturing crowns of human teeth dried in air;fragments werecollected, and those containing enamel were isolated. These were further reduced by cutting (fracturing) small enamel chips with stainless steel scissors. If dentine was approached, cutting was terminated and the remainder discarded. Great care was taken to prevent dentine contamination from the final ground sample.

Solids included enamel slabs having (a) unaitered, natural surfaces and (b) those with artificially flattened surfaces. Specimens were prepared from fresh, sound teeth supplied by the Oral Surgery Department, University of Michigan School of Dentistry. It was found that incisors, due to their relatively flat labial surface, yielded specimens of greatest enamel surface. Incisors thus constituted a greater proportion of the sample specimens than did canines, premolars or molars. For preparation of flattened slabs, teeth were embedded in modelling compound and thin slabs sliced off roughly parallel to the labial surface. Polishing was accomplished by a series of garnet polishing papers down to 6.0 grain. Of the 40 prepared specimens, 16 were selected for study on the basis of surface area, degree of flatness and lack of dentine contamination. Specimens were washed in water and dried in air prior to analysis. 
TABLE 1. SAMPLES ANALYSED BY INTERNAL REFLECTION SPECTROSCOPY (IRS)

I. Powders

A-Naturally occurring fluorapatites

(1) Bancroft, Ontario, Canada

(2) Oka, Quebec, Canada

(3) Durango, Mexico

(4) Holly Springs, Georgia, U.S.A.

(5) Ottawa, Quebec, Canada

B-Synthetic hydroxyapatite (Monsanto Co., St. Louis, Mo.)

C-Powdered enamel (5 specimens)

D-Reference inorganic compounds

(1) Calcium carbonate $\left(\mathrm{CaCO}_{3}\right)$

(2) Barium carbonate $\left(\mathrm{BaCO}_{3}\right)$

(3) Cadmium carbonate $\left(\mathrm{CdCO}_{3}\right)$

(4) Sodium pyrophosphate $\left(\mathrm{Na}_{4} \mathrm{P}_{2} \mathrm{O}_{7}\right)$

(5) Monobasic calcium phosphate $\left(\mathrm{Ca}\left(\mathrm{H}_{2} \mathrm{PO}_{4}\right)_{2}\right)$

(6) Dibasic calcium phosphate $\left(\mathrm{CaHPO}_{4}\right)$

(7) Tribasic calcium phosphate $\left(\mathrm{Ca}_{3}\left(\mathrm{PO}_{4}\right)_{2}\right)$

II. Solids

(8) Sodium tripolyphosphate $\left(\mathrm{Na}_{5} \mathrm{P}_{3} \mathrm{O}_{10}\right)$

A-Flattened enamel slabs (16 specimens)

B-Unaltered enamel slabs (2 specimens)

(1) Before disking

(2) After disking

Internal reflection spectra were obtained by use of multiple internal reflection KRS-5 (thallous-bromide, iodide) prisms mounted in a Wilks Model 45 Micro-ATR accessory. Prisms were trapezoidal in shape with angulation of $45^{\circ}$ between analytical surface and entrance face. Base-line spectra were run periodically to check for extraneous absorption (prism contaminants). Resultant spectra of prism and holder alone constituted control spectra. With powder analyses, samples were placed against both analytical surfaces of the KRS-5 prism whereas solids were placed against the smaller surface only. Enamel slabs were altered (flattened) in one phase of the study to allow multiple reflection with corresponding increased spectral resolution. The IRS attachment with enclosed sample was placed in the sample beam of a Perkin-Elmer 337 spectrophotometer for i.r. scanning from 2 to $25 \mu \mathrm{m}$. Unaltered enamel was scanned over an identical range using a single reflection apparatus (Courtesy of Wilks Scientific Corp.).

\section{RESULTS}

Five natural fluorapatites from different geographical locations yielded definitive spectra demonstrating strong phosphate absorption. Peaks varied over an $8 \mathrm{~cm}^{-1}$ range; however, band shapes were nearly identical. The asymmetric phosphorousoxygen stretch $\left(v_{3}\right)$ appeared as a doublet at approx. $1098 \mathrm{~cm}^{-1}$ and $1040 \mathrm{~cm}^{-1}$, the latter appearing as the deeper band (Fig. 1). The phosphorous-oxygen "symmetric" stretch $\left(v_{1}\right)$, which appears only because of lattice asymmetry, was seen at approximately $965 \mathrm{~cm}^{-1}$. The phosphorous-oxygen asymmetric bend $\left(v_{4}\right)$ was observed as a strong doublet (degeneracy having been lost) at approximately $603 \mathrm{~cm}^{-1}$ and 577 $\mathrm{cm}^{-1}$. Absorption at $630 \mathrm{~cm}^{-1}$ was not observed (Table 2).

Synthetic hydroxyapatite yielded similar spectra, except the $\nu_{1}$ peak at $963 \mathrm{~cm}^{-1}$ was weak relative to the $\nu_{3}$ doublet (Fig. 2). Also, a definite band was observed at $630 \mathrm{~cm}^{-1}$. The $v_{4}$ doublet was similar to that observed with natural fluorapatites. 
IRS OF ENAMEL

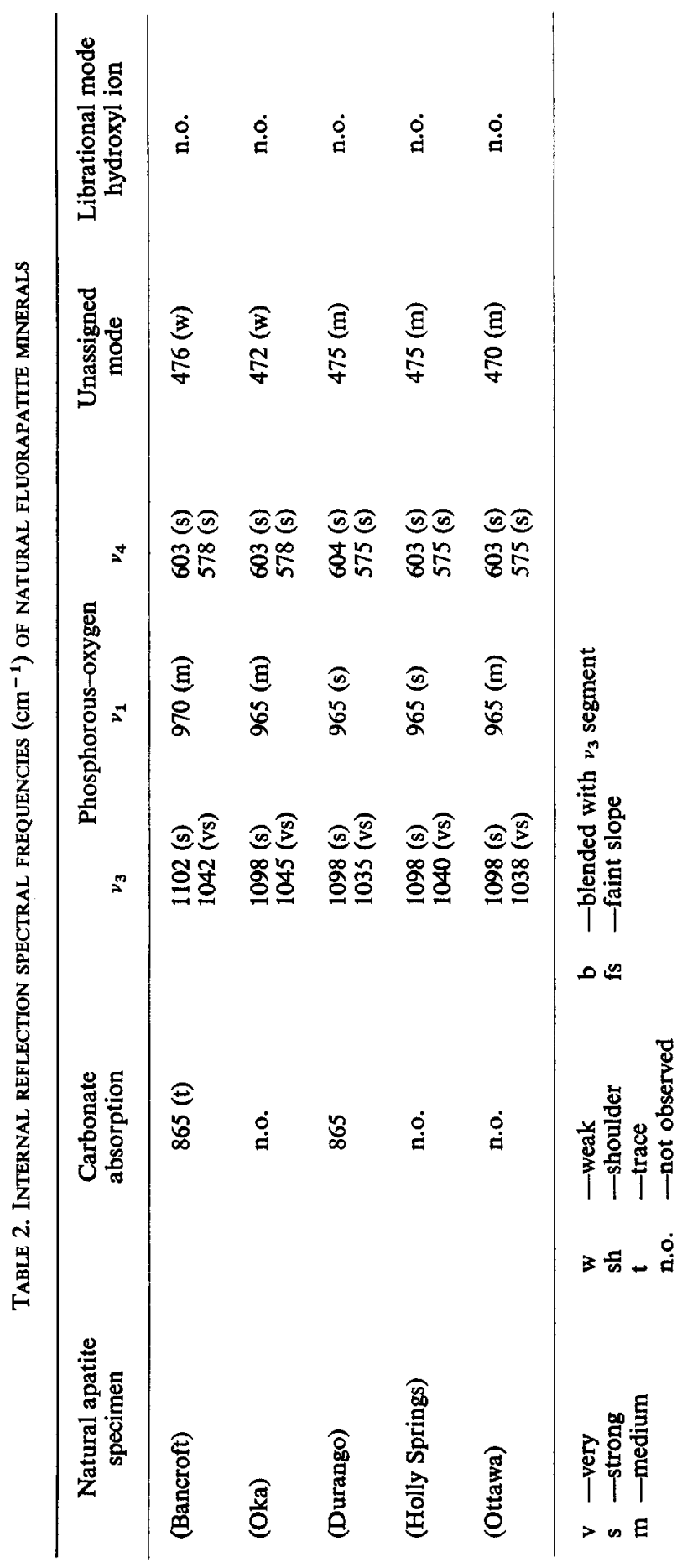




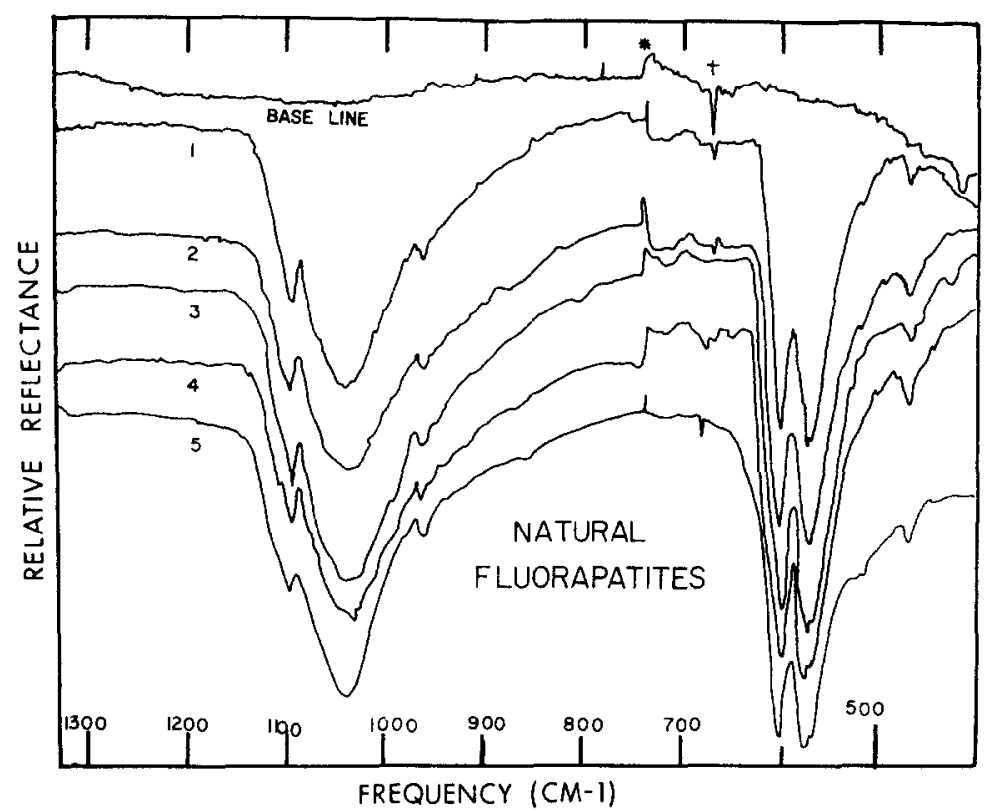

Fig. 1. Internal reflection spectra of powdered naturally occurring fluorapatites. Note lack of absorption at $630 \mathrm{~cm}^{-1}$ (Numbers 1-5 correspond to specimen origin as stated in Table 1).

*Artifact due to filter change at $740 \mathrm{~cm}^{-1}$.

+ Atmospheric $\mathrm{CO}_{2}$ absorption due to unequal path length of sample and reference beams.

$\emptyset$ Spectral irregularities from 1950 to $1350 \mathrm{~cm}^{-1}$ are due to atmospheric water vapor absorption.

Powdered enamel yielded consistent spectra in all samples tested (Figs. 3 and 4). Strongest absorption was a blunted peak in the $1020 \mathrm{~cm}^{-1}$ to $1040 \mathrm{~cm}^{-1}$ range. The $1090 \mathrm{~cm}^{-1}$ band was barely discernible and blended with the deeper $\nu_{3}$ segment. Another band (not observed with natural or synthetic apatites) was observed as a distinct peak between $870 \mathrm{~cm}^{-1}$ and $880 \mathrm{~cm}^{-1}$. A suggestion of absorption at 630 $\mathrm{cm}^{-1}$ was noted but seen in only 2 of 5 specimens, and when observed was extremely weak (Table 3).

Flattened enamel slabs demonstrated extremely broad absorption that was consistently deepest over a broad range ( $\left.900-990 \mathrm{~cm}^{-1}\right)$. Typical apatitic $\nu_{3}$ peaks were not observed. Enamel slabs, like enamel powder, demonstrated definitive absorption in the $860-880 \mathrm{~cm}^{-1}$ region. Weak absorption at $630 \mathrm{~cm}^{-1}$ was seen in some instances and not in others. $\nu_{4}$ peaks, although blunted, were consistent with those observed in spectra of enamel powders (Fig. 2).

Unaltered enamel surfaces yielded a shallow definitive peak at $1080 \mathrm{~cm}^{-1}$ with the deepest peak exhibiting blunted absorption at approx. $970-980 \mathrm{~cm}^{-1}$. Strong absorption at $950 \mathrm{~cm}^{-1}$ was also noted. The band at $870-880 \mathrm{~cm}^{-1}$ was observed with 


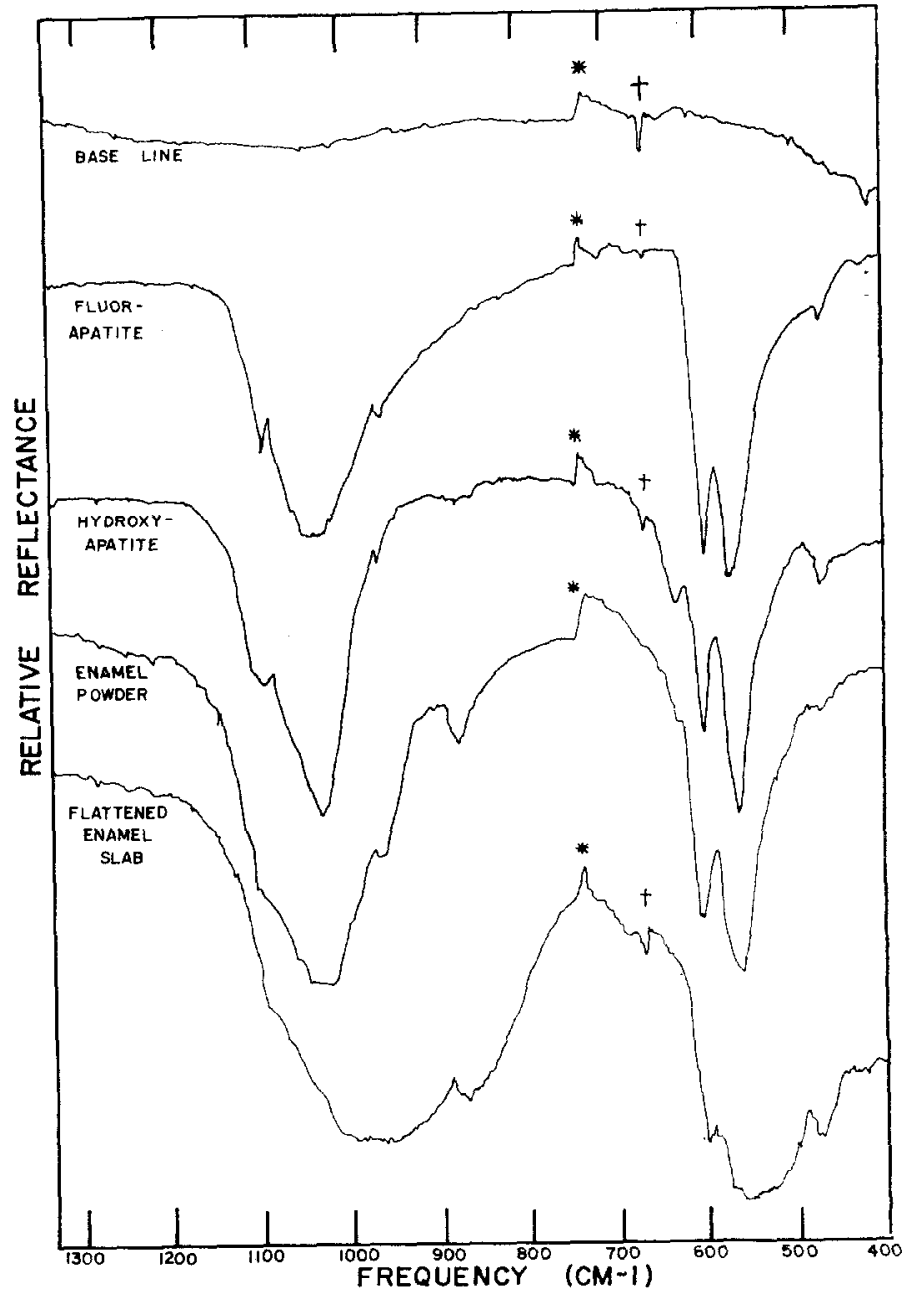

FIG. 2. Composite IRS spectra of fluorapatite, hydroxyapatite, powdered and intact enamel. Note broadening and distinct shift of absorption maximum in flattened enamel. 
D. J. KrutchKoff, N. H. Rowe AND H. B. MaRK, $\mathbf{J}_{\mathbf{R}}$.

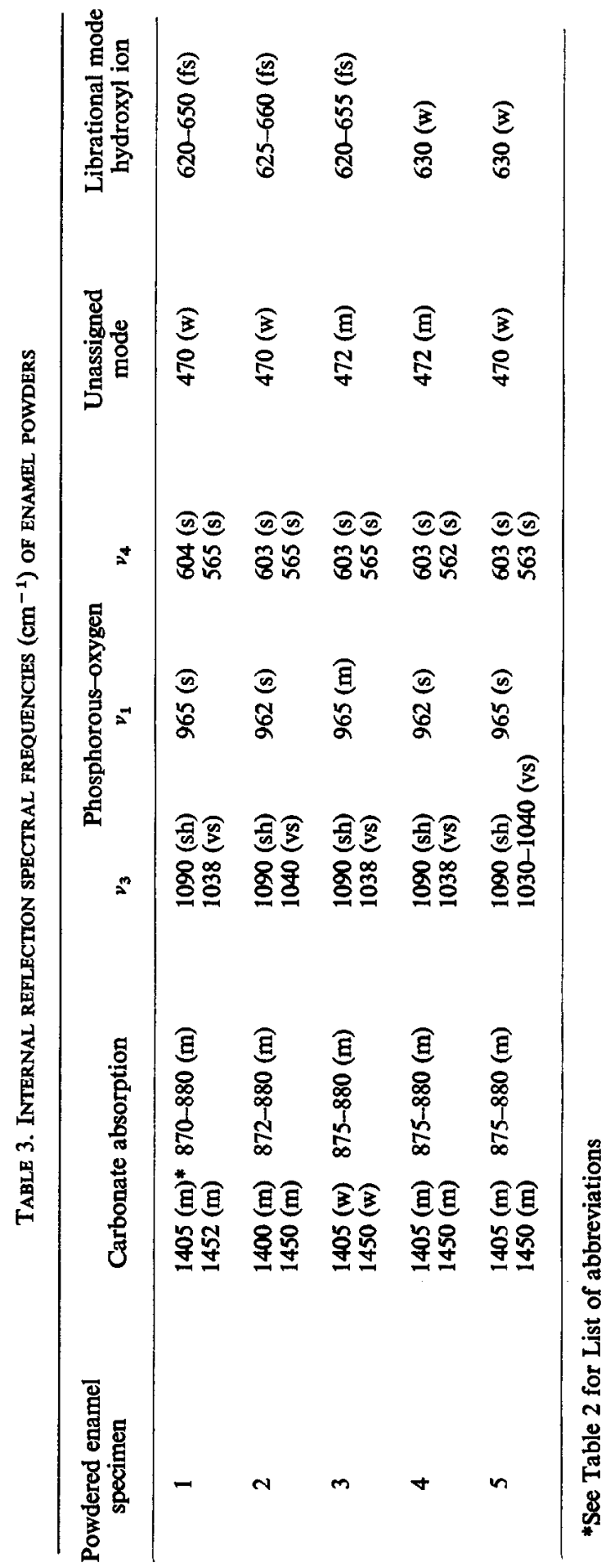




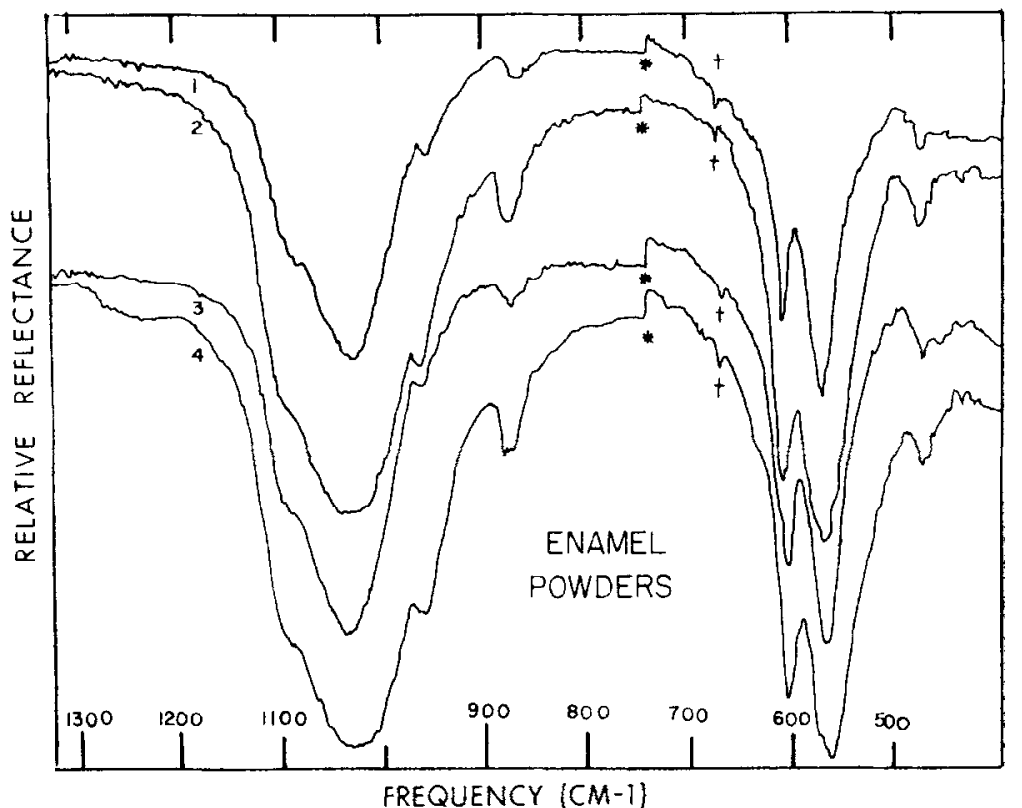

FIG. 3. Internal reflection spectra of four separate powdered enamel specimens. Note similarity to fluorapatites (see Fig. 1) with the exception of carbonate absorption at approximately $880 \mathrm{~cm}^{-1}$, and sloping approach to the $v_{4}$ band at $600 \mathrm{~cm}^{-1}$.

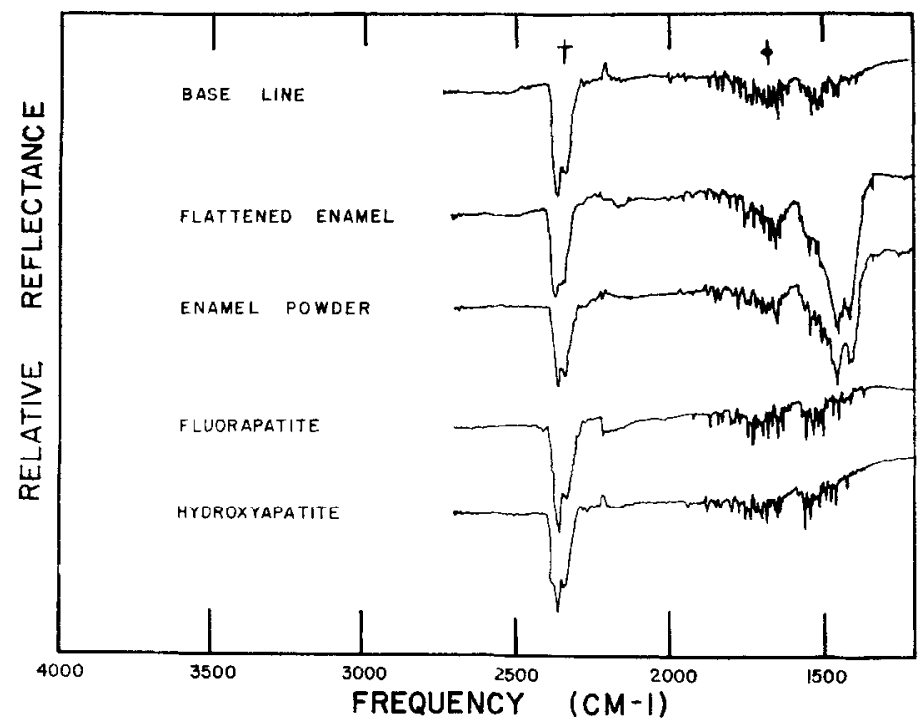

FIG. 4. Internal reflection spectra of representative apatite and enamel samples in higher energy region. Carbonate absorption at 1410 and $1450 \mathrm{~cm}^{-1}$ is readily A.o.B. $16 / 2-D$ noted in enamel specimens. 


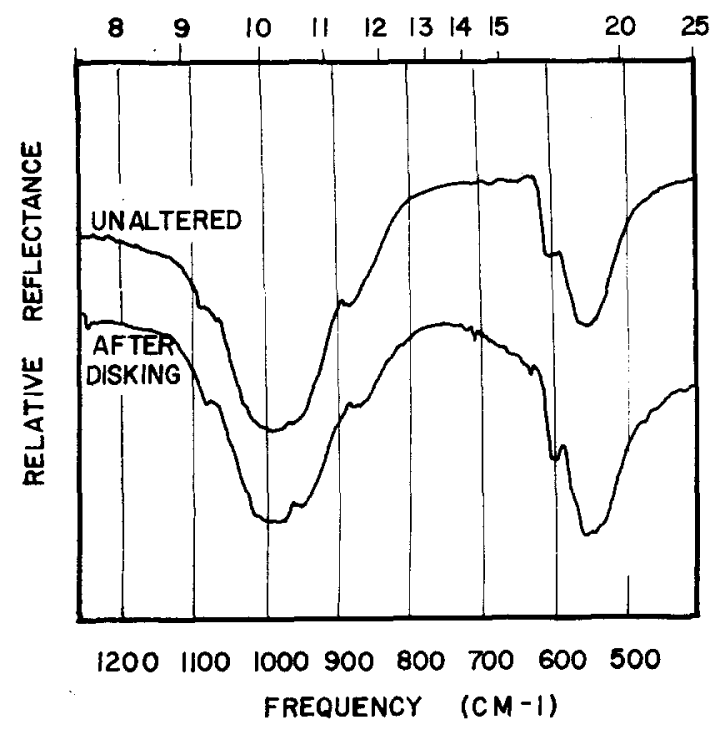

Fio. 5. Internal reflection spectra of enamel surface before and after disking. Note gradual downward slope and weak absorption at $630 \mathrm{~cm}^{-1}$ in disked enamel.

both flattened and natural enamel surfaces, while weak absorption at $630 \mathrm{~cm}^{-1}$ was an inconsistent observation (Fig. 5).

TABLE 4. COMPARISON OF TRANSMISSION AND INTERNAL REFLECTION METHODS (FREQUENCIES, $\mathrm{cm}^{-1}$ )

\begin{tabular}{lcc}
\hline \multicolumn{1}{c}{ Sample } & $\begin{array}{c}\text { Transmission } \\
\text { (Fowler, Moreno and Brown, 1966) }\end{array}$ & Internal reflection \\
\hline Dibasic calcium & $1128(\mathrm{~s})^{*}$ & \\
phosphate $\left(\mathrm{CaHPO}_{4}\right)$ & $1064(\mathrm{~s})$ & $1129(\mathrm{~s})$ \\
& $992(\mathrm{~m})$ & $1060(\mathrm{~s})$ \\
& $892(\mathrm{~m})$ & $990(\mathrm{~m})$ \\
& $576(\mathrm{~s})$ & $890(\mathrm{~m})$ \\
& $563(\mathrm{~s})$ & $580(\mathrm{sh})$ \\
Hydroxyapatite $_{\left(\mathrm{Ca}_{10}\left(\mathrm{PO}_{4}\right)_{6}(\mathrm{OH})_{2}\right)}$ & $525(\mathrm{~m})$ & $562(\mathrm{~s})$ \\
& $1092(\mathrm{~s})$ & $522(\mathrm{~m})$ \\
& $1040(\mathrm{vs})$ & $1090(\mathrm{~s})$ \\
& $962(\mathrm{w})$ & $1030(\mathrm{vs})$ \\
& $631(\mathrm{~m})$ & $965(\mathrm{~m})$ \\
& $601(\mathrm{~m})$ & $630(\mathrm{~m})$ \\
& $575(\mathrm{~m}, \mathrm{sh})$ & $600(\mathrm{~s})$ \\
& $561(\mathrm{~m})$ & n.o. \\
& $472(\mathrm{vw})$ & $560(\mathrm{~s})$ \\
& & $470(\mathrm{w})$ \\
\hline
\end{tabular}

*See Table 2 for list of abbreviations. 
IRS OF ENAMEL

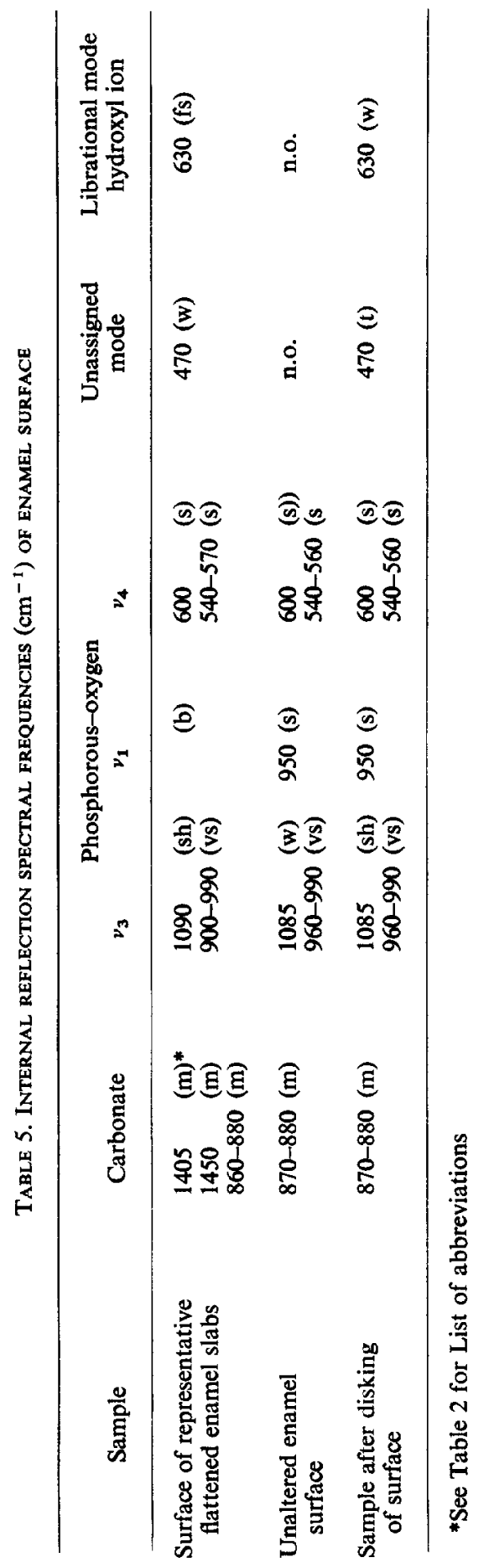




\section{DISCUSSION}

Spectra were highly reproducible when the experimental parameters of IRS were carefully controlled. Samples re-analysed on different occasions demonstrated band positions constant within a $3 \mathrm{~cm}^{-1}$ range (the approximate resolution limit of instrumentation used). In contrast to band position, absorption band depth varied from one analysis to the next. These changes in sensitivity were due to adjustable variables of the apparatus (e.g. gain, reference beam attenuation, beam alignment, slit width). Observed differences in absorption frequencies (e.g., spectra of fluorapatites) were attributed to real differences in samples rather than inconsistencies of technique.

The critical angle at the enamel-KRS-5 interface was approximately $42 \cdot 5^{\circ}$, (e.g., $\left.1 \cdot 62 / 2 \cdot 40=\operatorname{Sin} \theta_{c}\right)$. Thus at $\theta=45^{\circ}$, the critical angle was exceeded but only by minimal margin. Close proximity $\left(\theta\right.$ to $\left.\theta_{c}\right)$ is advantageous as it increases the penetration of incident energy into the rarer medium with corresponding greater opportunity for energy absorption. This advantage is countered by increasing distortion as refractive index varies through an absorption peak. Distortion (broadening on the long wavelength side of a band and shifts toward longer wavelengths) becomes significant only as theta closely approaches the critical angle (HARRICK, 1967). Under conditions of the present study, these distortion effects were considered to be minor.

An important variable of IRS is the efficiency of sample contact with the i.r.active prism surface. Powdered specimens of small particle size allowed for maximum contact between prism and sample. Under these conditions, multiple reflection was advantageous in that increased reflections occurred at areas of sample contact resulting in increased spectral resolution. In contrast, irregular solids, e.g., unaltered enamel surfaces) offered only a fraction of the surface area for prism contact. Multiple reflection analysis of unaltered enamel resulted in weak absorption and minimal attenuation since most of the source energy passed through the prism without opportunity for optical interaction with the sample. Thus, in the analysis of unaltered enamel surfaces (selected point contact), a single pass technique was employed. Optical properties of the single reflection hemicylinder of KRS- 5 served to converge the beam of incident energy (FAHRENFORT, 1961) to the area of contact. The subsequent reflection, although solitary, was then efficiently utilized. Spectra obtained by multiple reflection demonstrated no qualitative difference from those of single reflection methods. The only difference was sensitivity.

Transmission methods have been previously used in the i.r. characterization of apatites plus various related inorganic compounds (ELliotT, 1965; EMERSON, Fisher, 1962; Stutman, Termine and Posner, 1965; Winand, 1965). Analysis of reference minerals by IRS and subsequent comparison with transmission data clearly demonstrates similarity of results. Internal reflection spectra of synthetic hydroxyapatite reported here demonstrate absorption maxima within $10 \mathrm{~cm}^{-1}$ of transmission data reported by FoWLER, MORENO and BROWN (1966). In addition, IRS spectra of dibasic calcium phosphate reported here are similar to previously published transmission spectra (Fowler et al., 1966) (Table 4). Previous i.r. analysis of enamel utilizing transmission methods have suggested the presence of carbonate in enamel powder. In the discussion 
of enamel i.r. spectra, ElLioTt (1965) concluded that five of the observed bands were a result of carbonate absorption. IRS spectra of enamel powders and slab surfaces reported here demonstrate close agreement with Elliott's transmission data. Since structural differences in the vicinity of the phosphorous-oxygen bond have been reported to give rise to shifts in band frequency (STUTMan, TERMine and Posner, 1965), minor variations in band position between transmission and IRS spectra were attributed to slight difference in mineral species. Insensitivity of instrumentation or mild distortion due to proximity of theta to the critical angle are less likely but possible considerations.

Naturally occurring fluorapatites (identified by X-ray diffraction), although from different geographical locations (Mexico, Quebec, Georgia, Ontario, etc.), demonstrated a striking similarity of internal reflection spectra. These natural fluorapatites consistently failed to absorb at $630 \mathrm{~cm}^{-1}$. Absorption at such a frequency would indicate the hydroxy group since deuteration of hydroxyapatite has been reported to shift the $630 \mathrm{~cm}^{-1}$ band to $450 \mathrm{~cm}^{-1}$ (FowLer, 1968). Lack of absorption at 630 $\mathrm{cm}^{-1}$ is in agreement with the anticipated spectra of fluorapatite and demonstrates the ability of IRS to distinguish hydroxyapatite from fluorapatite.

Internal reflection spectra revealed differences related to the physical state of enamel samples. Powdered enamel specimens demonstrated $\nu_{3}$ absorption as a shoulder at $1090 \mathrm{~cm}^{-1}$ and a well-defined peak in the $1030-1040 \mathrm{~cm}^{-1}$ range. The $\nu_{1}$ symmetric stretch was consistently observed at approx. $965 \mathrm{~cm}^{-1}$. In contrast, spectra of solid enamel (both altered and unaltered slabs) demonstrated a distinct shift in absorption maxima. Components of the $\nu_{3}$ mode tended to merge, with a resultant broadening and loss of definition of band position. Maximum absorption was no longer seen in the 1030-1040 $\mathrm{cm}^{-1}$ range, but shifted to the $900-990 \mathrm{~cm}^{-1}$ range as a poorly defined doublet. An adequate explanation for this effect was not apparent although refractive index, degree of sample contact and differences in crystalline or chemical nature were among the factors considered.

The $v_{4}$ absorption (asymmetric phosphorous-oxygen bend) was observed consistently as a split degeneracy. One segment occurred in the $600-603 \mathrm{~cm}^{-1}$ range, as a sharp, well-defined peak. The other was variable in shape between $540 \mathrm{~cm}-^{1}$ and $570 \mathrm{~cm}^{-1}$ depending upon the physical state of the enamel specimen. With powdered enamel, the variable (low energy) $v_{4}$ segment was sharp and consistently resolved within a narrow range $\left(562-565 \mathrm{~cm}^{-1}\right)$. In contrast, spectra of intact enamel demonstrated an ill-defined absorption maximum over a broadened range $\left(540-570 \mathrm{~cm}^{-1}\right)$. The explanation of this phenomenon awaits further investigation.

To accomplish IRS analysis of unaltered enamel surfaces, it was necessary to diminish the i.r.-active prism surface to the approximate area of sample contact. The resultant single reflection spectrum provided adequate characterization of unaltered enamel, surfaces. Subsequent disking of surface enamel resulted in slight but perceptable spectral changes as demonstrated by IRS. Unaltered enamel demonstrated a level approach to the $\nu_{4}$ absorption followed by an abrupt drop at $610 \mathrm{~cm}^{-1}$ to a welldefined peak at $600 \mathrm{~cm}^{-1}$. After disking, absorption increased gradually at about $780 \mathrm{~cm}^{-1}$ and continued into a weak band at $630 \mathrm{~cm}^{-1}$. Absorption increased from 
this point to the characteristic $\nu_{4}$ band at $600 \mathrm{~cm}^{-1}$ (Table 5, Fig. 5). This change was attributed to relative loss of fluorapatite at the enamel surface due to mechanical reduction to subsurface levels.

The future direction of IRS in enamel research will include single reflection, and, eventually, multiple reflection in-vivo analysis. In-vivo testing will require refinement of experimental apparatus, eg., sample holders, etc., and selection of relatively inert prism materials (KRS-5 is toxic).

Acknowledgements-We wish to thank Dr. D. A. PEACoR, Department of Geology and Mineralogy for kindly supplying natural mineral samples, and Drs. THOMAS SchiFf and K. Y. KIM, Monsanto Corp., St. Louis, Missouri, for their gift of synthetic hydroxyapatite. Technical assistance and equipment used for single reflection analyses was generously provided by the Wilks Scientific Corporation, S. Norwalk, Conn. and is gratefully acknowledged. We also wish to thank Dr. JOSEPH SINSHEIMER, Department of Pharmaceutical Chemistry, for use of spectrophotometric equipment.

This investigation was supported in part by Grant 5 FO3 DE 39678-03 (postdoctoral fellowship) from the National Institute of Dental Research, USPHS. This paper was presented at the 48th Annual Meeting of the IADR in New York City, 16-19 March, 1970.

Résumé--Les techniques utilisées pour l'analyse chimique de la surface de l'émail ne permettent généralement pas des essais in vivo. Au cours de cette étude, l'intérêt de la spectroscopie par reflexion interne (IRS) a été testé en tant que méthode non-destructive pour l'analyse de la surface de l'émail.

Des poudres (émail mélangé à des produits inorganiques connus) et des solides (fragments d'émail plat et non altéré) sont analysés par IRS. La plupart des échantillons sont montés sur un accessoire du modèle Wilks 45 Micro-ATR et étudiés par balayage de 2-25 $\mu \mathrm{m}$ pour obtenir un spectre IR. Une absorption $\nu_{3}$ phosphore-oxygène, typique de l'apatite, est observée à $1090 \mathrm{~cm}^{-1}$ et $1040 \mathrm{~cm}^{-1}$ dans le spectre de fluoroapatites naturels et poudres d'émail. Des différences de spectres sont observées entre l'émail intact et en poudre. La présence de carbonate est confirmée pour ces deux types d'émail. La surface d'ćmail intacte et les fluorapatites n'absorbent pas à $630 \mathrm{~cm} . .^{-1}$ Une faible absorption à $630 \mathrm{~cm}^{-1}$, après meulage de la surface de l'émail, est interprêtée comme une perte relative de fluoroapatite, liée à la mise à nu de la sub-surface. L'IRS permet de mettre en évidence de faibles différences chimiques de la surface de l'émail. Cette méthode non-destructive parait intéressante pour des analyses de surfaces d'émail in vivo.

Zusammenfassung-Die früher zur chemischen Analyse der Schmelzoberfiäche benützten Methoden sind im allgemeinen für in-vivo-Untersuchungen ungeeignet. Diese Studie betraf die Eignung der internen Reflektionspektroskopie (IRS) als eine nicht-destruktive Methode für Analysen der Schmelzoberfläche.

Mit Hilfe der IRS wurden Pulver (Schmelz plus anorganisches Referenzmaterial) und Festkörper (abgeflachte und unveränderte Schmelzplatten) analysiert. Die meisten Proben wurden in ein Wilks Modell 45 Micro-ATR-Zubehör montiert und von 2-25 $\mu \mathrm{m}$ gerastert, um IR-Spektra zu erhalten. Die Vergleichbarkeit der IRS-Ergebnisse mit denen von Transmissionsmethoden wurde nachgewiesen. In den Spektra von natürlichen Fluorapatiten und Schmelzpulvern wurde die typische apatitische $\nu_{3}$ PhosphorSauerstoffabsorption bei $1090 \mathrm{~cm}^{-1}$ und $1040 \mathrm{~cm}^{-1}$ beobachtet. Spektraldifferenzen gab es zwischen gemahlenem und intaktem Schmelz. Die Anwesenheit von Karbonat ließ sich sowohl in gemahlenem als auch im intakten Schmelz bestätigen. Die intakte Schmelzoberflächs und Fluorapatite zeigten bei $630 \mathrm{~cm}^{-1}$ keine Absorption. Eine 
schwache Absorption bei $630 \mathrm{~cm}^{-1}$ nach Abschleifen der Schmelzoberfläche wurde als ein relativer Verlust von Fluorapatit als Folge mechanischer Reduktion auf unter der Oberfläche gelegene Abschnitte interpretiert. Die IRS ermöglichte es, feinste chemische Unterschiede in der Schmelzoberfläche zu erkennen. Diese nichtdestruktive Methode scheint daher für Analysen der Schmelzoberfläche in vivo vielversprechend zu sein.

\section{REFERENCES}

Battistone, G. C., Feldman, M. H. and ReBA, R. C. 1967. The manganese content of human enamel and dentine. Archs oral Biol. 12, 1115-1122.

BRudevold, F., Steadman, L. T. and SMITH, F. A. 1960. Inorganic and organic components of tooth structure. Ann. N.Y. Acad. Sci. 85, 110-132.

CRISLER, R. O. 1966. Infra-red in the industrial laboratory. In Applied Infra-red Spectroscopy, pp. 377-396 (edited by KendaLl, D. N.) Rheinhold, New York, 1965.

ELLIOTT, J. C. 1965. The interpretations of the infra-red absorption spectra of some carbonatecontaining apatites. In Tooth Enamel, 219 pp. (edited by STACK, M. V. and FearnHEAD, R. W.) Wright, Bristol.

EMERSON, W. H., Fischer, E. E. 1962. Infra-red absorption spectra of carbonate in calcified tissues. Archs oral Biol. 7, 671-683.

FAHRENFORT, J. 1961. Attenuated total reflection-A new principal for the production of useful infra-red reflection spectra of organic compounds. Spectrochim. Acta 17, 698-709.

FowLRR, B. O. Sept. 12-14, 1968. Infra-red spectroscopy of Apatites. Abstr. Internat. Symposium of Structural Properties of Hydroxyapatite and Related Compounds, Gaithersberg, Md.

Fowler, B. O., Moreno, E. C. and Brown, E. E. 1966. Infra-red spectra of hydroxyapatite, octacalcium phosphate and pyrolsed octacalcium phosphate. Archs oral Biol. 11, 477-92.

Frank, R. M., Capitant, M. and Goni, J. 1966. Electron probe studies of human enamel. J. dent. Res. 45, 672-682 (Supp.).

HARRICK, N. J. 1967. Internal Reflection Spectroscopy, 327 pp. Wiley, New York.

HertzBerg, G. 1945. Molecular Spectra and Molecular Structure, Vol. 2 Chapt. 2. Van Nostrand, New York.

Hoffman, S., McEwan, W. S. and Drew, C. M. 1968. Scanning electron microscopy of dental enamel. Abstr. J. dent. Res. 47, 842.

IsaAC, S., Brudevold, F., Smith, F. A. and Gardner, D. E. 1958. The relation of fluoride in the drinking water to the distribution of fluoride in enamel. J. dent. Res. 37, 318-325.

KENDALL, D. N. 1966. Infra-red radiation: description and simple theory of absorption by molecules. In Applied Infra-red Spectroscopy, pp. 10-30 (edited by KendaLL, D. N.) Rheinhold, New York.

Mellberg, J. R. Nicholson, C. R., Miller, B. G. and Englander, H. R. 1968. Acquisition of fluoride in-vivo by enamel from repeated topical sodium fluoride applications in a fluoridated area: a preliminary report. J. dent. Res. 47, 733-36.

PolchlopeK, S. E. 1966. Attenuated total reflectance. Applied Infra-red Spectroscopy, pp. 463-484 (edited by Kendall, D. N.) Rheinhold, New York.

SöremarK, R. and GRøN, P. 1966. Chloride distribution in human dental enamel as determined by electron probe microanalysis. Archs oral Biol. 11, 861-66.

Stutman, J. M., Termine, J. O. and Posner, A. S. 1965. Vibrational spectra of the phosphate ion in some calcium phosphates. Trans. N.Y. Acad. Sci. 27, 669-75.

Winand, L. 1965. Physio-chemical study of some apatitic phosphates. In Tooth Enamel, pp. 15-19 (edited by Stack, M. V. and Fearnhead, R. W.) Wright, Bristol. 